\title{
Corrigendum: The effectiveness of US energy efficiency building labels
}

Omar Isaac Asensio and Magali A. Delmas

Nature Energy 2, 17033 (2017); published 27 March 2017; corrected 11 April 2017.

In the version of this Article originally published, the value in the first sentence was misattributed to the United States and should have referred to global emissions. The sentence has been updated to 'Energy supplied in buildings accounts for an estimated 8.8 gigatons of $\mathrm{CO}_{2}$ emissions globally or about one-third of total energy use and carbon emissions'. 